\title{
Pengaruh Komunikasi Interpersonal dan Kecerdasan Emosional terhadap Stres pada Karyawan
}

\author{
PAULIA JAUZA RIZKI \& FAJRIANTHI* \\ Fakultas Psikologi Universitas Airlangga
}

\begin{abstract}
ABSTRAK
Penelitian ini bertujuan untuk mengetahui pengaruh komunikasi interpersonal dan kecerdasan emosional terhadap kecenderungan stres pada karyawan. Penelitian ini dilakukan kepada 86 karyawan tetap di suatu perusahaan dan memiliki durasi kerja tidak kurang dari dua tahun yang terdiri dari 52 laki-laki dan 34 perempuan. Alat ukur dalam penelitian ini menggunakan Perceived Stress Scale 10 item, The Assessing Emotional Scale (AES) 33 item, dan Komunikasi Interpersonal 23 item. Setelahnya data dianalisis menggunakan program software IBM SPSS statistic 22 for windows melalui uji regresi linear sederhana dan berganda. Hasil menunjukan bahwa komunikasi interpersonal berpengaruh negatif dan signifikan terhadap stres pada karyawan (Sig. 0,03<0,05). Selanjutnya kecerdasan emosional memiliki pengaruh negatif yang signifikan terhadap stres karyawan (Sig. 0,034<0,05). Komunikasi interpersonal dan kecerdasan emosional secara simultan berpengaruh terhadap stres pada karyawan.
\end{abstract}

Kata kunci: karyawan, kecerdasan emosional, komunikasi interpersonal, stres

\section{ABSTRACT}

This study is accomplished to reveal the effect of interpersonal communication and emotional intelligence on stress tendencies in employees. This research was conducted on 86 permanent employees in a company and had a working duration of not less than two years consisting of 52 men and 34 women. The measuring instrument in this study used a 10-item Perceived Stress Scale, 33 items The Assessing Emotional Scale (AES), and 23 items Interpersonal Communication. After that, the data were analyzed using the IBM SPSS statistics 22 for windows software program through simple and multiple linear regression tests. The results show that interpersonal communication has a negative and significant effect on stress on employees (Sig. $0.03<0.05$ ). Furthermore, emotional intelligence has a significant negative effect on employee stress (Sig. $0.034<0.05$ ). Interpersonal communication and emotional intelligence simultaneously affect stress on employees.

Keywords: employee, emotional intelligence, interpersonal communication, stress

Buletin Penelitian Psikologi dan Kesehatan Mental (BRPKM), 2021, Vol. 1(1), 569-576

*Alamat korespondensi: Fakultas Psikologi Universitas Airlangga, Kampus B Universitas Airlangga Jalan Airlangga 4-6 Surabaya 60286. Surel: fajrianthi@psikologi.unair.ac.id 


\section{PEN D A H U L U A N}

Stres merupakan fenomena yang tidak jarang dialami oleh karyawan. Stres timbul akibat adanya tekanan dan kondisi yang tidak sesuai dengan apa yang diharapkan terjadi. Fenomena stres yang terjadi di perusahaan tidak memberikan dampak positif baik bagi karyawan maupun perusahaan. Lembaga kesehatan dunia WHO (World Health Organization) menganggap adanya penyakit pada abad ke 20 yang mengindikasikan bahwa stres kerja menjadi lebih banyak terjadi di hampir setiap pekerjaan di seluruh dunia yang telah menjadi epidemi global. Lebih dari setengah (64\%) pekerja di Indonesia mengalami peningkatan stress dibanding pada tahun lalu (Puspandhani, 2020)

Di Indonesia beberapa penelitian menunjukan fenomena yang menggambarkan stres kerja pada bagian produksi perusahaan manufaktur diketahui bahwa setengah atau $50 \%$ dari responden yang diteliti mengalami stres sedang, kemudian sebanyak 6,9\% responden mengalami stres kerja sangat berat dan sisinya 16,7\% mengalami stres ringan (Puspandhani, 2020). Stres digambarkan dengan adanya sebuah stimulus yang terlihat di lingkungan sekitar individu yang kemudian diinterpretasikan sesuai dengan pengalaman individu pada munculnya respon emosional baik secara biologis maupun psikologis (Herbert \& Cohen, 1993).

Hasil berbagai survei menunjukan bahwa indikasi stres terjadi pada pekerja salah satunya perusahaan manufaktur (Airmayanti, 2009). Efek stres juga memungkinkan terjadinya dampak subjektif, perilaku, kognitif, fisiologis, kesehatan dan dampak organisasional (Hermita, 2011). Terdapat indikator stres terjadi antaranya perasaan yang tidak terprediksi (feeling of unpredictability), perasaan tidak terkontrol (feeling of uncontrollability) dan perasaan tertekan secara berlebihan (feeling of overloaded) (Cohen, Kamarck, \& Mermelstein, 1983). Berdasarkan indikator terhadap stres maka ditemukan juga beberapa penelitian yang menghubungkan stres dengan komunikasi interpersonal. Komunikasi interpersonal dapat mempengaruhi stres kerja pada karyawan, agar mampu mengetahui stres kerja yang dihadapi seorang karyawan maka individu berusaha untuk berpikir positif pada rekan kerja dan bisa melakukan kerjasama yang baik serta mampu untuk memberikan apresiasi sebagai bentuk empati ke sesama rekan kerja (Yunita \& Purba, 2020). Komunikasi interpersonal merupakan suatu proses pengiriman dan penerimaan pesan antara dua orang atau sekumpulan orang dengan saling memberikan umpan balik (Devito, 2017). Komunikasi interpersonal dapat mempengaruhi stres kerja, untuk mampu mengetahui stres kerja yang dihadapi seorang karyawan maka individu berusaha untuk berpikir positif pada rekan kerja dan bisa melakukan kerjasama yang baik serta mampu untuk memberikan apresiasi sebagai bentuk empati ke sesama rekan kerja (Yunita \& Purba, 2020).

Selain komunikasi interpersonal, peneliti juga menemukan adanya hubungan kecerdasan emosional dengan stres yang dialami karyawan. Kecerdasan emosional memiliki hubungan terhadap stres kerja, kecerdasan yang tinggi bagi karyawan sangat bermanfaat karena dapat mencegah masalah dengan memiliki strategi yang sesuai dan dapat menghilangkan konflik sehingga stres dengan mudah untuk diatasi dengan baik (Setiyawan, 2005). Kecerdasan emosional diartikan sebagai proses pengambilan sebuah keputusan caranya adalah dengan mengontrol emosi, meningkatkan kesadaran diri, serta menjaga hubungan orang lain dan kecerdasan emosional karyawan merupakan sebuah kemampuan untuk mengontrol emosi yang diperlukan untuk mengelola stres kerja (Nezad \& Bahramzade, 2013) penelitian tersebut menjelaskan bahwa kecerdasan emosional penting dimiliki oleh karyawan dalam memberi respon yang terjadi ketika sedang mengalami situasi tertekan.

Sehingga, penelitian ini bertujuan untuk melihat pengaruh komunikasi interpersonal dan kecerdasan emosional terhadap stres pada karyawan. Mengingat bahwa karyawan dengan tekanan pekerjaan tinggi seperti karyawan manufaktur berpotensi memiliki tekanan kerja yang cenderung akan lebih membuat 
stres karyawan. Sehingga perlu dirasa untuk melihat pengaruh terhadap stres pada karyawan sehingga nantinya dapat menjadi perhatian bagi perusahaan. Selain itu, diperkuat dari penelitian yang dilakukan sebelumnya mengatakan hampir semua pekerjaan memiliki stressor yang mengakibatkan munculnya stres kerja yang dapat mempengaruhi performa dari karyawan. ketika kecerdasan emosional rendah, maka akan terbentuk sikap untuk bertindak secara negatif dalam menjalani pekerjaan (Akbar, 2013).

\section{Stres Pada Karyawan}

Stres merupakan keadaan internal yang diakibatkan oleh tuntutan fisik dari tubuh atau kondisi lingkungan dan sosial yang dinilai potensial membahayakan, tidak terkendali atau melebihi kemampuan individu untuk mengatasinya (Cohen, 1994). Terdapat tiga indikator yang menjelaskan stres yang menggambarkan bahwa stres yang terjadi pada karyawan akibat tekanan dari aspek eksternal atau lingkungan. Lingkungan yang memberi dampak seperti kondisi kerja, rekan dan tekanan pekerjaan, sehingga hal tersebut terjadi hingga tidak dapat dikontrol. Dapat diindikasikan bahwa stres dapat menimbulkan tekanan pada karyawan yang berdampak pada penurunan performa dan keadaan tidak seimbang internal individu dalam kehidupannya. Disebutkan tiga indikator tersebut, antara lain perasaan yang tidak terprediksi, perasaan yang tidak terkontrol dan perasaan tertekan secara berlebihan (Cohen, Kamarck, \& Mermelstein, 1983).

\section{Komunikasi Interpersonal}

Komunikasi sebagai kemampuan karyawan dalam melakukan proses pengiriman dan penerimaan pesan atau informan ada orang lain yang melibatkan sikap dan perilaku (Devito, 2017). Karakteristik di dalam komunikasi interpersonal ini terjadi dari individu ke orang lain, komunikasi tatap muka dalam bentuk menggambarkan karakteristik pribadi karyawan dalam peran sosial. Komunikasi interpersonal penting dimiliki oleh karyawan guna membantu mereka dalam mengkonfirmasi informasi yang diterima atau dimiliki sebagai bentuk karyawan dalam menurunkan stres. Adapun indikator yang terdapat dalam komunikasi interpersonal antara lain keterbukaan, empati, sikap mendukung, sikap positif, kesetaraan, keyakinan, dan kesiapan (Devito, 2011)

\section{Kecerdasan Emosional}

Kecerdasan Emosional merupakan sebuah kemampuan agar dapat merasakan, menilai dan mengekspresikan emosi atau disebut sebagai kemampuan untuk membangkitkan perasaan (Mayer, Salovey, \& Caruso, 2004). Kecerdasan emosi juga merupakan pengetahuan tentang emosi serta bagaimana individu dalam menaikan intelektual yang dimiliki (Dharmariana, 2015).

\section{Karyawan}

Pengertian dari karyawan sendiri adalah manusia yang menggunakan kemampuannya untuk melakukan pekerjaan guna mendapatkan balasan berupa pendapatan dalam bentuk uang maupun bentuk lainnya kepada pemberi kerja. Sebelum karyawan tersebut menerima imbalan mereka harus menyelesaikan tugas dan kewajiban yang harus diselesaikan. karakteristik dari karyawan dalam penelitian ini adalah mereka yang sudah bekerja tidak kurang dari dua tahun dan menjadi karyawan tetap.

Berdasarkan dari penjelasan mengenai stres, komunikasi interpersonal, dan kecerdasan emosional. Penelitian ini terdapat hipotesis sebagai berikut:

$\mathrm{H}_{1}$ : komunikasi interpersonal mempengaruhi stres karyawan

$\mathrm{H}_{2}$ : kecerdasan emosional mempengaruhi stres karyawan

$\mathrm{H}_{3}$ : komunikasi interpersonal dan kecerdasan emosional mempengaruhi stres karyawan

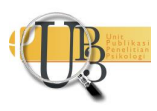




\section{MET OD E}

\section{Desain Penelitian}

Pada penelitian ini menggunakan penelitian kuantitatif yang digunakan untuk meneliti suatu populasi tertentu yang bertujuan untuk menjelaskan atau menguji sebuah hipotesis dalam penelitian (Sugiyono, 2008). Teknik pengumpulan data dalam penelitian ini berupa kuesioner skala. Metode yang digunakan adalah kuantitatif eksplanatif karena akan melihat penjelasan mengenai alasan suatu terjadi dan menguji hipotesis (Priyono, 2016). Jika berdasarkan waktu penelitian ini tergolong penelitian crosssectional.

\section{Partisipan}

Partisipan pada penelitian ini merupakan karyawan yang bekerja setidaknya tidak kurang dari dua tahun dan merupakan karyawan tetap diperusahaan. Penelitian ini menggunakan teknik non probability sampling dengan jenis accidental sampling. Sebelum melakukan pengambilan data, partisipan terlebih dahulu dihimbau untuk mengisi informed consent.

Jumlah partisipan dalam penelitian ini berjumlah 86 (dengan persentase laki-laki 60,5\% dan perempuan 39,5\%) yaitu sebanyak 52 laki-laki dan 34 perempuan. Rentang usia didominasi rentang 2630 tahun (sebesar 65,11\%) dan jenjang pendidikan terakhir S1 sejumlah 34 partisipan (sebesar 39,5\%).

\section{Pengukuran}

Dalam melakukan pengukuran stres menggunakan Perceived Stress Scale yang sudah diadaptasi dan diuji reliabilitas dan validitasnya (Hary, 2017). Skala ini terdiri dari sepuluh item yang disusun dengan menggunakan skala likert dengan rentang respon 1 sampai 4. (1 = Sangat Tidak Setuju , 2= Tidak Setuju , 3= Setuju, 4= Sangat Setuju). Dalam mengukur komunikasi interpersonal skala telah di uji dan diadaptasi untuk mengukur komunikasi interpersonal karyawan (Ayuni, 2018). Skala ini terdiri dari 23 item yang disusun dengan menggunakan skala likert dengan rentang respon 1 sampai 4 . 1 = Sangat Tidak Setuju , 2= Tidak Setuju , 3= Setuju, 4= Sangat Setuju). Dalam mengukur kecerdasan emosional menggunakan Assessing Emotional Scale (AES) yang sudah diadaptasi dan diuji reliabilitas dan validitasnya (Dharmariana, 2015). Skala ini terdiri dari 33 item yang disusun dengan menggunakan skala likert dengan rentang respon 1 sampai 4. (1 = Sangat Tidak Setuju , 2= Tidak Setuju , 3= Setuju, 4= Sangat Setuju).Validitas alat ukur Perceived Stress Scale pada penelitian ini telah di uji oleh (Hary, 2017). Validitas alat ukur komunikasi interpersonal telah diuji oleh (Ayuni, 2018). Validitas alat ukur Assessing Emotional Scale (AES) pada penelitian ini telah diuji oleh (Dharmariana, 2015). Teknik yang digunakan dalam mengukur validitas alat ukur dalam penelitian ini adalah dengan content validity

Reliabilitas sudah diukur dengan menggunakan Cronbach's Alpha. Skala komunikasi interpersonal terdiri dari 23 item dengan koefisien reliabilitas yang cukup baik $(\alpha=.0,74)$. Skala Assessing Emotional Scale (AES) terdiri dari 33 item dengan koefisien reliabilitas yang cukup baik $(\alpha=.0,86)$. Kemudian pada skala Perceived Stress Scale terdiri dari 10 item dengan koefisien reliabilitas yang cukup baik $(\alpha=.0,81)$. Ketiga skala yang digunakan dalam penelitian ini memenuhi syarat reliabilitas. 


\section{Analisis Data}

Uji asumsi yang dilakukan menunjukan bahwa sebaran data adalah normal dan linear. Uji multikolinearitas yang dilakukan dalam penelitian ini menunjukan bahwa tidak terdapat korelasi atau hubungan antar variabel independen pada model regresi. Kemudian selanjutnya uji heteroskedastisitas berdasarkan gambar scatter plots regression tidak mengindikasi kesamaan variance dari residual satu pengamatan ke pengamatan lainnya. Maka dari itu data dalam penelitian ini memenuhi semua asumsi dan selanjutnya dianalisis menggunakan analisis regresi linear sederhana dan berganda. Dalam mengolah data tersebut digunakan software IBM SPSS statistic 22 for windows.

\section{HAS I L P EN ELITIAN}

Hasil analisis deskriptif menunjukan bahwa partisipan yang memiliki komunikasi interpersonal yang tinggi sebanyak 11 orang dengan persentase (12,8\%), sedang sebanyak 57 partisipan (62,3\%) dan rendah sebanyak 18 partisipan (24,9\%). Untuk kategori kecerdasan emosional tinggi sebanyak 11 partisipan (12,8\%), sedang 65 partisipan $(75,6 \%)$ dan rendah 10 paritisipan (11,6\%). Sedangkan, pada kategori stres yang tinggi sebanyak 13 partisipan $(15,1 \%)$ sedang 60 partisipan $(69,8 \%)$ dan rendah sebanyak 13 partisipan $(15,1 \%)$.

Hasil analisis regresi linear sederhana antara komunikasi interpersonal terhadap stres menunjukan bahwa komunikasi interpersonal dapat menjelaskan stres pada karyawan sebesar 9,7\% (F $\left.(1,84)=9.064 ; p<0,05 ; R^{2=} 0,097\right)$. Komunikasi interpersonal secara signifikan berpengaruh dengan sifat negatif terhadap stres pada karyawan $(\beta=-0,312 ; p<0,05)$.

Hasil analisis regresi linear sederhana antara kecerdasan emosional terhadap stres pada karyawan menunjukan bahwa kecerdasan emosional dapat menjelaskan stres pada karyawan sebesar 5,2\% ( F $\left(1,84=4.654 ; p<0,05 ; R^{2}=0.052\right)$. kecerdasan emosional secara signifikan berpengaruh dengan sifat negative terhadap stres pada karyawan $(\beta=-0,229 ; p<0,05)$.

Selanjutnya, hasil analisis regresi linear berganda menunjukan bahwa komunikasi interpersonal dan

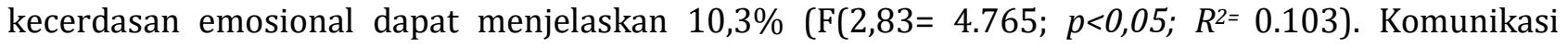
interpersonal secara signifikan berpengaruh terhadap stres ada karyawan $(\beta=-0,108 ; p<0,05)$. Begitu pula kecerdasan emosional yang juga memiliki pengaruh stres pada karyawan $(\beta=-0,028 ; p<0,05)$.

\section{I S K U S I}

Tujuan dari penelitian ini adalah untuk melihat pengaruh komunikasi interpersonal dan kecerdasan emosional terhadap stres pada karyawan. Dari analisis yang sudah dilakukan, dapat ditemukan bahwa hasil menunjukan komunikasi interpersonal memiliki pengaruh negatif yang signifikan terhadap stres pada karyawan. Berdasarkan dari analisis data terdapat sumbangsih sebesar 97\% komunikasi interpersonal mempengaruhi stres pada karyawan dan selebihnya dipengaruhi oleh faktor lain yang tidak menjadi bagian dari penelitian ini.

Hasil penelitian juga memperkuat pernyataan bahwa komunikasi merupakan pengiriman dan penerimaan pesan di antara dua orang atau sekelompok orang dengan memberikan umpan balik. Komunikasi yang efektif adalah komunikasi yang memberikan pengaruh tertentu sesuai dengan tujuan yang diharapkan (Devito, 2017). Hal tersebut memberi arti bahwa kemampuan komunikasi interpersonal memiliki pengaruh yang signifikan terhadap kecenderungan stres pada karyawan.

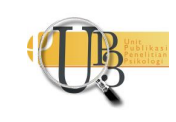


masing- masing dari penyebab stres tertentu akan bekerja untuk menghilangkan atau mengurangi stres kerja. Langkah-langkah akan diambil untuk mengurangi stres kerja. Misalnya, dalam bidang kebijakan. Hal yang sama akan dilakukan pada bidang fisik (misalnya, komunikasi dan berbagai informasi akan ditingkatkan, dan ambigu atau hal-hal yang bertentangan akan diklarifikasi atau diselesaikan). Berdasarkan dari penjelasan diatas maka dapat diketahui bahwa komunikasi dan berbagai informasi (komunikasi interpersonal) ditingkatkan sebagai salah satu strategi untuk mengurangi stres kerja (Lindawati, 2014).

Selanjutnya dari analisis regresi yang sudah dilakukan, ditemukan hasil yang memperlihatkan bahwa kecerdasan emosional memiliki pengaruh yang signifikan terhadap stres pada karyawan, dengan sumbangsih pengaruh yang diberikan sebesar 5,2\% dan selebihnya dipengaruhi oleh faktor lain yang tidak menjadi bagian dari penelitian ini.

Hal ini dapat memperkuat pernyataan bahwa kecerdasan emosional merupakan kemampuan untuk memonitor perasaan dan emosi diri sendiri dan orang lain, membedakannya dan menggunakan informasi emosi tersebut untuk memandu proses berpikir dan bertingkah laku (Mayer \& Salovey, 1995). Karyawan akan lebih mudah merespon dan kembali di keadaan normal jika memiliki kecakapan yang cukup dalam hal kecerdasan emosionalnya. Kecerdasan emosional merupakan komponen yang membuat seseorang mampu menggunakan emosi dengan baik. Ketika seseorang dapat menggunakan kecerdasan emosional dalam melakukan pekerjaan maka karyawan bisa menyelesaikan tugasnya dengan efisien. Hal ini juga sejalan dengan penelitian terdahulu, kecerdasan emosional berpengaruh negatif signifikan terhadap stres kerja yang dihadapi oleh karyawan. Hasil menunjukkan bahwa karyawan yang memiliki kecerdasan emosional yang tinggi maka stres kerja akan rendah sehingga mampu meningkatkan kerja yang optimal bagi individu (Wulandari, Yulianeu, \& Warso, 2017).

Kemudian yang terakhir, berdasarkan analisis regresi yang sudah dilakukan, ditemukan hasil yang menunjukan bahwa variabel komunikasi interpersonal dan variabel kecerdasan emosional secara bersama sama atau dengan kata lain simultan memiliki pengaruh yang signifikan terhadap stres pada karyawan. Sumbangsih kontribusi yang lebih besar ada pada komunikasi interpersonal yaitu -0.028.

\section{S I M P U L A N}

Berdasarkan penelitian yang sudah dilakukan, hal yang dapat disimpulkan dalam penelitian ini adalah sebagai berikut, komunikasi interpersonal memiliki pengaruh dengan sifat negatif yang signifikan terhadap stres pada karyawan. Selanjutnya, ditemukan bahwa kecerdasan emosional memiliki pengaruh dengan sifat yang negatif terhadap stres pada karyawan. Komunikasi interpersonal dan kecerdasan emosional bersama-sama memiliki pengaruh dengan sifat yang negatif terhadap stres pada karyawan. Kontribusi sumbangsih yang paling besar dari kedua variabel tersebut terdapat pada komunikasi interpersonal.

Saran untuk penelitian selanjutnya adalah diharapkan peneliti dapat menjelaskan dinamika dari variabel lain selain komunikasi interpersonal dan kecerdasan emosional yang sekiranya dapat memprediksi stres pada karyawan. Peneliti selanjutnya juga diharapkan menggunakan partisipan dengan jumlah yang lebih besar agar bisa menjelaskan informasi yang mendalam. Selain itu diharapkan agar lebih detail dalam menjelaskan dinamika partisipan dengan menggunakan alat ukur yang telah disesuaikan pada jamannya agar lebih bisa menjelaskan fenomena yang terjadi. Saran untuk perusahaan agar kedepan bisa lebih memperhatikan kesejahteraan karyawannya baik dari aspek gaji, tunjangan maupun hari libur. Perusahaan juga diharapkan mampu memberikan ruang komunikasi antar karyawan agar bisa saling meningkatkan kemampuan komunikasi interpersonal. 


\section{U C A P A N T ERIMAKASIH}

Terima kasih penulis ucapkan kepada Allah SWT, keluarga, sahabat dan rekan-rekan serta kepada semua pihak yang sudah terlibat dalam memberi dukungan dan membantu dalam proses penelitian ini hingga selesai.

\section{DEKLARASI POTENSI TERJADINYAKONFLIK KEPENTINGAN}

Paulia Jauza Rizki dan Fajrianthi tidak bekerja, menjadi konsultan, memiliki saham, atau menerima dana dari perusahaan atau organisasi maupun yang mungkin akan mengambil untung dari diterbitkannya naskah ini.

\section{PUSTAKA ACUAN}

Airmayanti, D. (2009). Faktor-Faktor yang Mempengaruhi Stres Kerja pada Pekerja bagian Produksi PT ISM Bogasari Flour Mills, Tbk Tahun 2009. Skripsi. UIN Syarif Hidayatullah Jakarta.

Akbar, S. N. (2013). HUBUNGAN ANTARA KECERDASAN EMOSI DENGAN STRES KERJA PADA PERAWAT. Skripsi. Universitas Lambung Mangkurat.

Ayuni, P. (2018). KOMUNIKASI INTERPERSONAL DAN KEPUASAN KERJA PADA KARYAWAN PT. DJARUM DI KUDUS. Skripsi. UNIVERSITAS ISLAM INDONESIA.

Cohen, S. (1994). Perceived Stress Scale. Mind Garden. Retrieved from https://www.mindgarden.com/documents/PerceivedStressScale.pdf

Cohen, S., Kamarck, T., \& Mermelstein, R. (1983). A global measure of perceived stress. Journal of Health and Social Behavior, 24(4), 385-396.

Devito, J. A. (2011). Komunikasi Antarmanusia -5/E. Tangerang: Karisma Publishing Group.

Devito, J. A. (2017). The Interpersonal Communication Book (15th ed.). Boston: Pearson Education, Inc.

Dharmariana, J. R. (2015). Hubungan Antara Kecerdasan Emosional dengan Adaptibilitas Karir Pada Mahasiswa Akhir. Skripsi. Universitas Airlangga.

Hary, Z. A. P. (2017). Hubungan antara kelekatan terhadap ibu dengan tingkat stres pada mahasiswa perantau. Skripsi. Universitas Sanata Dharma.

Herbert, T. B., \& Cohen, S. (1993). Stress and immunity in humans: a meta-analytic review. Psychosomatic Medicine, 55(4), 364-379. https://doi.org/10.1097/00006842-199307000-00004

Hermita. (2011). PENGARUH STRES KERJA TERHADAP KINERJA KARYAWAN PADA PT. SEMEN TONASA (PERSERO) PANGKEP. Skripsi. UNIVERSITAS HASANUDDIN.

Lindawati, R. D. (2014). Pengaruh Komunikasi Interpersonal Dan Stres Kerja Terhadap Komitmen

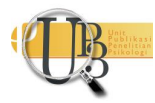


Organisasi Pegawai Pusdiklat Bea Dan Cukai. Jurnal Manajemen Pendidikan UNJ, 5(1). Retrieved from https://docplayer.info/71260070-Pengaruh-komunikasi-interpersonal-dan-stres-kerjaterhadap-komitmen-organisasi-pegawai-pusdiklat-bea-dan-cukai.html

Mayer, J. D., \& Salovey, P. (1995). Emotional intelligence and the construction and regulation of feelings. Applied and Preventive Psychology, 4(3), 197-208. https://doi.org/10.1016/S09621849(05)80058-7

Mayer, J. D., Salovey, P., \& Caruso, D. R. (2004). TARGET ARTICLES: “Emotional Intelligence: Theory, Findings, and Implications." Psychological Inquiry, 15(3), 197-215. https://doi.org/10.1207/s15327965pli1503_02

Nezad, F. S., \& Bahramzade, M. R. (2013). Relationship between emotional intelligence and job satisfaction. European Online Journal of Natural and Social Sciences, 2(3). Retrieved from https://european-science.com/eojnss/article/view/559

Priyono. (2016). BUKU METODE PENELITIAN KUANTITATIF. Sidoarjo: Zifatama.

Puspandhani, M. E. (2020). STRES KERJA DITINJAU DARI SIFT KERJA PADA PEKERJA BAGIAN PRODUKSI PT PERUSAHAAN MANUFAKTUR KOTA CIREBON TAHUN 2020. Journal Scientic of $\begin{array}{llll}\text { Mandalika } & \text { (JSM), } & \text { Retrieved } & \text { from }\end{array}$ http://ojs.cahayamandalika.com/index.php/jomla/article/view/289

Setiyawan, E. (2005). Hubungan Antara Kecerdasan Emosional dengan Prestasi Kerja. Skripsi (Tidak Diterbitkan). Surakarta: Fakultas Psikologi Universitas Muhammadiyah Surakarta.

Sugiyono. (2008). Metode penelitian pendidikan:(pendekatan kuantitatif, kualitatif dan $R$ \& D). Bandung: Alfabeta.

Wulandari, D., Yulianeu, Y., \& Warso, M. M. (2017). PENGARUH KECERDASAN EMOSIONAL TERHADAP STRES KERJA MELALUI EFIKASI DIRI (Studi Kasus Pada Sekolah Luar Biasa Negeri Semarang). Journal of Management, 3(3). Retrieved from http://docplayer.info/48010652-Pengaruhkecerdasan-emosional-terhadap-stres-kerja-melalui-efikasi-diri-studi-kasus-pada-sekolah-luarbiasa-negeri-semarang.html

Yunita, D., \& Purba, A. W. D. (2020). HUBUNGAN PERSEPSI KOMUNIKASI INTERPERSONAL DENGAN STRES KERJA PADA KARYAWAN PT. WESEN JAYATAMA CABANG MEDAN. Islamika Granada, 1(1), $1-7$. 